\title{
Spectrum Occupancy Measurements in Cellular Frequency Band in Samsun
}

\author{
Begüm Korunur Engiz and Yousif Ali Rajab
}

\begin{abstract}
In this study, available spectrum parts in GSM900, LTE800, LTE900, GSM1800, LTE1800, UMTS2100 and LTE2600 were determined. The measurement campaigns were performed at 115 different locations in Samsun city center at the most active time of a day using RF Explorer 6G Combo analyzer device. The spectrum utilization rates were determined using energy detection technique (EDT), and average spectrum occupancy technique (ASOT). The thresholds were chosen manually as $-40,-45,-50,-55,-60,-65,-70,-75 \mathrm{dBm}$, and as 10-dB above the noise floor, as recommended by International Telecommunication Union (ITU), and spectrum utilization was evaluated through EDT and ASOT. Obtained results show that at most of the measurement locations spectrum occupancy percentages calculated via EDT and ASOT very close to each other. Based on the results UMTS2100 band showed the highest average spectrum occupancy i.e. $33.91 \%$ and the overall average spectrum occupancy rate was found to $22.72 \%$. Additionally, at $50 \%$ of the measurement locations occupancy percentage was below $33 \%$ for all services. The average occupancy over GSM900 band was between $0.87 \%$ - $66.61 \%$ according to the predetermined threshold. It was also found that the bands LTE1800 and LTE2600 were mostly occupied for the thresholds below $-60 \mathrm{dBm}$ whereas the measured spectrum was mostly vacant for $-40 \mathrm{dBm}$. This led us to infer that there is a great potential for share some of UHF band for cognitive radio applications and future $5 \mathrm{G}$ systems.
\end{abstract}

Index Terms - Average Spectrum Occupancy Technique, Cognitive Radio, Energy Detecting Technique, Spectrum Occupancy Measurement

\section{INTRODUCTION}

$\mathrm{I}^{\mathrm{n}}$ $\mathrm{n}$ order to meet the growing demand for wireless communication systems and applications, operators are pushed to establish new techniques to solve the shortage of radio spectrum resources problem. Efficient utilization of

BEGÜM KORUNUR ENGİ, is with Department of Electrical and Electronics Engineering, Ondokuz Mayıs University, Samsun, Turkey,(e-mail: bkengiz@omu.edu.tr).

iD https://orcid.org/0000-0002-3905-1791

YOUSIF ALI RAJAB, is with Department of Electrical Engineering, Sakarya University, Sakarya. Turkey (e-mail: yousif.ali.rajab@gmail.com).

iD https://orcid.org/0000-0002-8186-3742

Manuscript received January 24, 2021; accepted March 29,2021

2018. DOI: $10.17694 /$ bajece. 867294 radio frequency spectrum of fundamental importance. During recent years, the rapid increase in the number of users around the world has led the enormous growth of wireless applications and services to be developed [1]. However, there is less opportunity to find an available band (spatially or temporally) to deploy new wireless communication services or improve the existing ones.

Cognitive radio (CR) stands out as a promising solution for the competent administration an access control to the spectrum [2]. The concept of $\mathrm{CR}$ based on allowing so-called unlicensed, secondary user, for access to spectrum bands that are available, without make interference with the primary user [3]. In order to allow access, and deployment of CR, unused part of the spectrum must be determined. In [4], TV white space spectrum was evaluated for VHF (174-230 MHz) and UHF bands (470-860 MHz), in 8 different urban environment locations in Prishtina, the capital of Republic of Kosovo by using the NARDA Selective Radiation Meter SRM-3006. It is shown in the study that availability of TV bands varies between $87.5 \%$ and $100 \%$, and give the opportunistic use of spectrum by CR. Available Television White Space (TVWS) spectrums in Samsun were determined in [5] with the aid of measurements conducted within $470 \mathrm{MHz}-790 \mathrm{MHz}$ band at 73 different locations. The maximum spectrum occupancy was found as $70 \%$ while the average spectrum occupancy was 20.7\%. For long-term spectrum monitoring and occupancy, a study was performed by [6] within the band $174 \mathrm{MHz}$ and $1000 \mathrm{MHz}$. This study proves that big portions of spectrum are free, and suitable for spectrum sharing. Also, multi-band and multi-location spectrum measurements campaign conducted in Nigeria in $80-2200 \mathrm{MHz}$ frequency range in [7], and it was shown that the actual spectral occupancy in Nigeria was less than $10.00 \%$. Furthermore, it was evaluated through spectral occupancy measurements conducted in Konya, Turkey from 30 to $3000 \mathrm{MHz}$ frequency range that many frequency bands are suitable for CR [8]. Available spectrum in the Global Mobile Communications (GSM) $900 \mathrm{MHz}$ band in Palestine was validated through the simulations, and an efficient and interference robust CR system was proposed [9]. Unused spectrum parts in GSM900 band are evaluated through outdoor spectrum measurements performed in Samsun, and spectral usage in the band was found as $8.5 \%$ for $-40 \mathrm{dBm}$ [10]. For instance, the spectrum occupancy measurements carried out in South Africa for UHF, GSM900 MHz and GSM1800 MHz bands. Occupancy in the UHF band was approximately $20 \%$ while the GSM900 and $1800 \mathrm{MHz}$ bands were occupied $92 \%$ and $40 \%$ respectively [11]. Similar study 
carried out in Kampala for GSM900, GSM1800, and the universal mobile telecommunications system 2100 (UMTS2100) and long term evolution 2600 (LTE2600) bands in [12]. The result of the study indicated an average uplink occupancy rate for GSM900, GSM1800, UMTS2100 and LTE2 100 bands are of $8.8 \%, 0.6 \%, 0.56 \%$ and $0 \%$ respectively. Spectrum experiments were conducted in Barcelona for the frequencies of $75 \mathrm{MHz}$ to $3 \mathrm{GHz}$ [13]. The spectrum usage in Beijing was determined through continuous $24 \mathrm{~h}$ measurements over the frequencies from 450 to 2700 $\mathrm{MHz}$ [14], and shown that GSM900 band had the highest occupancy with $45.52 \%$. The spectrum occupancy measurements were performed in three different locations. The target band was sub- $6 \mathrm{GHz}$, and the results show that the average duty cycle of the sub- $6 \mathrm{GHz}$ is $4.73 \%$ [15]. In order to determine the spectrum occupancy, the measurements conducted within $850 \mathrm{MHz}$ to $2 \mathrm{GHz}$ using Software Radio Peripheral. Energy detection method was used with the threshold $6 \mathrm{~dB}$ above the noise floor. Average occupancy is calculated as $17.3 \%$ and opportunities for CR systems were determined [2]. The spectrum measurements performed at frequency band of $700 \mathrm{MHz}$ to $2.7 \mathrm{GHz}$ in India for indoor and outdoor using DA5000 that is a compact discone aerial antenna and R\&S FSH3 Handheld Spectrum Analyzer (HSA) connected to a laptop. Indoor and outdoor spectrum occupancies were examined and compared. According to results that the use of spectrum was very low, and spectrum was available for CR [16]. Spectrum measurements were conducted in Czech Republic and France at three different regions for the frequencies within $400 \mathrm{MHz}-3 \mathrm{GHz}$. The average occupancies at three different regions were found as $6.5 \%, 10.7 \%$ and $7.7 \%$ [17]. In [18], the spectrum in the frequency range $50 \mathrm{MHz}-6 \mathrm{GHz}$ was scanned using deep radio based RF measurement systems. The spectrum usage analysis showed that a large amount of spectrum in the Digital Video Broadcasting (DVB) and GSM bands were underutilized, and occupied bandwidth percentages in many cellular bands were low. The relationship between spectrum detection performance and antenna numbers in MIMO systems was examined in [19]. The simulation results showed that the increase in the antenna numbers yielded better detection performance and channel capacity.

In this study, in order to determine the spectrum occupancy within cellular frequency bands (range from $700 \mathrm{MHz}-2.7$ $\mathrm{GHz}$ ) widespread measurements were conducted in Samsun - Turkey using RF Explorer 6G Combo spectrum analyzer. Spectrum occupancies were calculated by applying energy detecting and average spectrum occupancy techniques. The rest of the paper is organized as follows. Brief description of measurement setup is given in Section 2, measurement and occupancy results were presented in Section 3, and the paper is concluded in the final section.

\section{MATERIAL AND METHOD}

In this study in order to find the holes within cellular frequency bands, widespread spectrum measurements conducted at various locations in Samsun-Turkey with an estimated area of 7 square kilometers. The measurements were performed using RF Explorer 6G Combo spectrum analyzer, and the results were recorded. Then, the recorded data which represent the measurement data from all measurement locations was assessed through MATLAB. Spectrum occupancies were calculated at chosen thresholds through EDT and ASOT. The details of the measurement process and spectrum occupancy calculation are given in the following sections.

\section{A. Spectrum Measurement}

In order to have the necessary knowledge about the current spectrum usage in Samsun province, 115 locations were selected for coverage of all city center. Measurements were performed within the band $700 \mathrm{MHz}$ to $2700 \mathrm{MHz}$ that contain all cellular frequency bands, 2G capabilities GSM900, GSM1800, 3G capabilities UMTS2100, 4G capabilities LTE800, LTE900, LTE1800, and LTE2600.

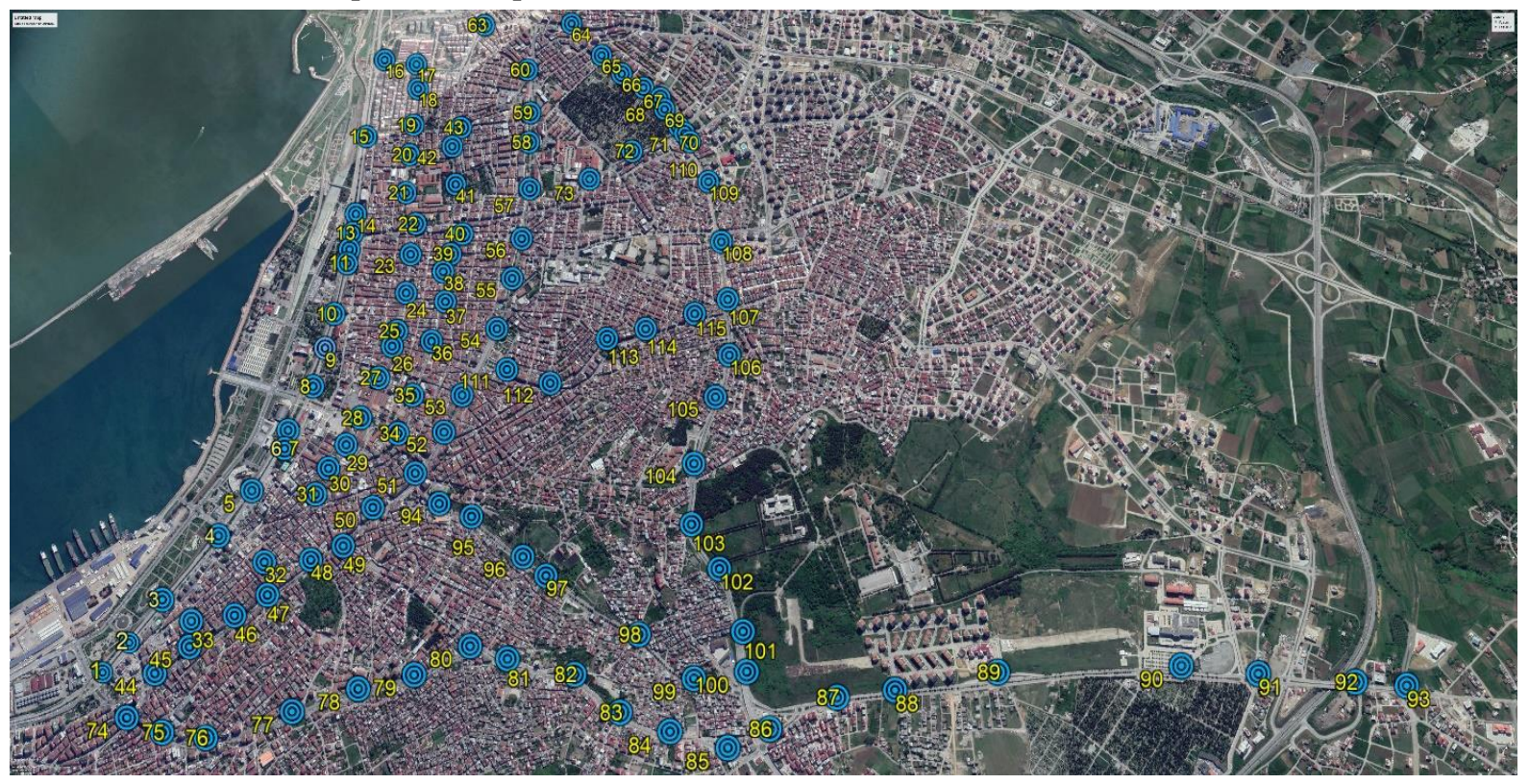

Fig. 1. Measurement locations 
The measurements were taken from 1 August 2018 to 7 August 2018, in the busiest hours of a day starting from 6:00 pm to 10:00 pm. Measurement locations are shown in Fig. 1, service names and measured frequencies are given in Table I.

TABLE I

THE TARGETED CELLULAR FREQUENCY BANDS

\begin{tabular}{|c|c|c|c|}
\hline Index & $\begin{array}{c}\text { Service } \\
\text { Name }\end{array}$ & $\begin{array}{c}\text { Lower } \\
\text { Frequency } \\
\text { (MHz) }\end{array}$ & $\begin{array}{c}\text { Upper } \\
\text { Frequency } \\
\text { (MHz) }\end{array}$ \\
\hline 1 & LTE800 & 791 & 820.9 \\
\hline 2 & LTE900 & 925.1 & 935.1 \\
\hline 3 & GSM900 & 935.1 & 961.0 \\
\hline 4 & GSM1800 & 1805 & 1820 \\
\hline 5 & LTE1800 & 1820 & 1879 \\
\hline 6 & UMTS2100 & 2010 & 2120 \\
\hline 7 & LTE2600 & 2570 & 2670 \\
\hline
\end{tabular}

Measurements were taken using RF Explorer 6G Combo spectrum analyzer. After installing device's Open Source software, and connecting dongle to the laptop, the device will be ready to take measurements. The software shows radio frequency spectrum bandwidth including Normal, Peak Max, Max Hold, Overwrite and Averaging modes. Span of the analyzer is $0.112-600 \mathrm{MHz}$ and $2-600 \mathrm{MHz}$, and frequency range is $15-2700 \mathrm{MHz}$ and $4850-6100 \mathrm{MHz}$ according the antennas used. Frequency resolution is $1 \mathrm{kHz}$ and average noise level is $-105 \mathrm{dBm}$. RF Explorer 6G Combo spectrum analyzer's software enables the follow the change in received signal strength and detection of the empty band by saving the instantaneous power in $\mathrm{dBm}$. Measurement setup and an image of spectrum measurement with analyzer is shown in Fig. 2.

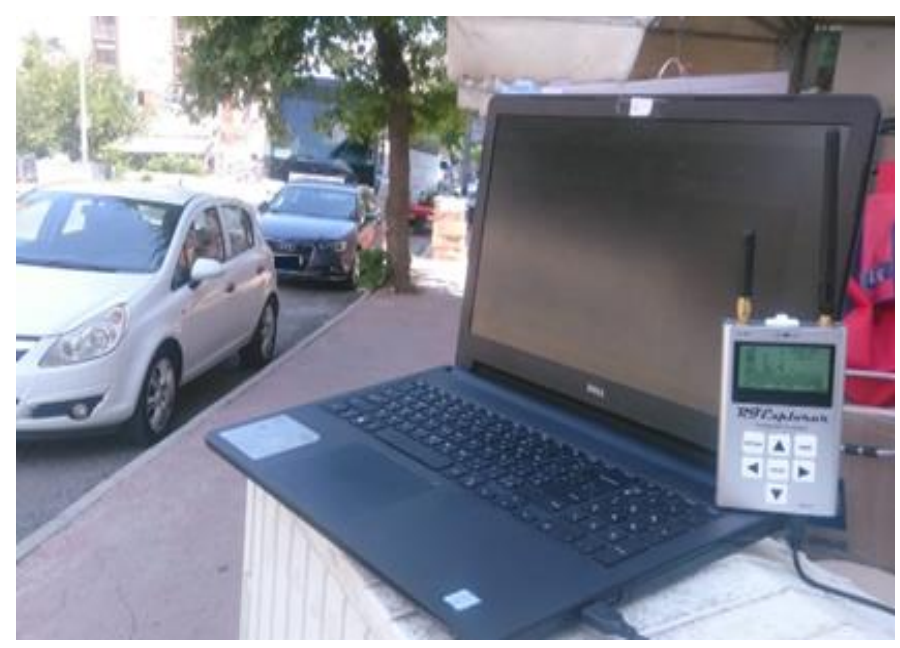

Fig. 2. An example of spectrum measurement with spectrum analyzer

\section{B. Occupancy Calculation Methods}

In this study, the first technique that followed to determine the unused spectrum parts is Energy Detection Technique (EDT). In EDT, the spectrum is considered as occupied if the received signal power is above a certain threshold. Then the occupation rate of communication channels or frequency band can be determined according to the measurement's location and time. Because EDT has low computational complexity, and easy to implement it is widely applied. After the completion of the measurements, the average power of the specific frequency at the location is calculated using (1).

$$
P_{\text {avg }}=\sum_{i=1}^{m} \frac{p_{i}}{m}
$$

Where: the average power is represented by $P_{\text {avg, }}$ number of reading times presented by $m$, and the power of specific frequency at a specific moment is shown by $p_{i}$. In a measurement, the spectrum occupancy is calculated through (2):

$$
F_{\left(f_{i}, p_{i}\right)}=\left\{\begin{array}{l}
0, p_{i}<\beta \\
1, p_{i} \geq \beta
\end{array}\right.
$$

In the equation, $F_{\left(f_{\left.i, p_{i}\right)}\right.}$ shows the spectrum occupancy at a measurement frequency, $\beta$ is the threshold, and $p_{i}$ is the average power. Then, if $L$ shows the number of frequency span, the band's average spectrum occupancy is calculated using (3).

$$
F_{\text {avg }}=\sum_{i=1}^{L} \frac{F_{\left(f_{i}, p_{i}\right)}}{L}
$$

The second is; average spectrum occupancy technique (ASOT) that depends on finding the spectrum occupancy rate for a frequency point at specific time slot determined by equation (4).

$$
\phi_{f(n)_{t} t(s)}=\left\{\begin{array}{l}
0, p_{n}<\beta \\
1, p_{n} \geq \beta
\end{array}\right.
$$

In the equation, $\phi_{f(n) t[s)}$ shows the spectrum occupancy of specific frequency point $f(n)$ at time slot $t(s)$, and $p_{n}$ represents the received power spectral density measured in specific frequency point, and $\beta$ presents the threshold.

After finding the spectrum occupancy for each frequency point, spectrum occupancy of a band in all time slots can be determined through (5).

$$
\phi=\frac{1}{m k} \sum_{s=1}^{m} \sum_{n=1}^{k} \phi_{f(n), t(s)}
$$

Where: $\phi$ is the average spectrum occupancy, $m$ is the total number of time samples at a frequency, and $k$ is the number of the frequency points in the chosen band.

In order to apply the methods above; the thresholds should be determined. In this study two different methods were used to determine the thresholds. First, seven different threshold value was selected manually as $-40 \mathrm{dBm},-45 \mathrm{dBm},-50 \mathrm{dBm}$, $-60 \mathrm{dBm},-65 \mathrm{dBm},-70 \mathrm{dBm},-75 \mathrm{dBm}$. In the second 
method, to determine the noise floor (NF); power spectral density values of individual frequencies are averaged over time and the median is taken. Then $\mathrm{M} d B$, ITU recommendation is $10 \mathrm{~dB}$ for spectrum monitoring, was added to the NF value to set the threshold. After the determination of the thresholds, spectrum occupancy percentages were calculated using both methods and results were given in the following section.

\section{RESULTS AND DISCUSSIONS}

In order to detect available parts of the spectrum, detailed measurements were conducted within cellular frequency bands, then techniques that described in the previous section have been applied. For the sake of brevity, figure for EDT at $-55 \mathrm{~dB}$ for all services is given in Fig. 3. Overall occupancy evaluations are shown in stacked bar plot (Fig. 4.a, and Fig. 4.b) for EDT and ASOT respectively. It can be seen from Fig. 3 that spectrum utilization varies significantly by location and the service. The maximum average occupancies are $85.71 \%$, $100 \%, 80 \%, 80 \%, 54.55 \%, 66.67 \%$, and $15.52 \%$ for the services of LTE800, LTE900, GSM900, GSM1800, LTE1800, UMTS2100 and LTE2600 respectively. The figure also indicates that utilization level of LTE2600 band is very low. It can be concluded from Fig. 4 that average occupancy percentages vary from $0.05 \%$ to $85.22 \%$ for all services considered. Additionally, LTE800 and UMTS2100 bands are highly occupied, and GSM900, GSM1800 bands are almost equally occupied for all thresholds. Furthermore, the overall average occupancy of the services are $1.02 \%, 2.79 \%, 8.08 \%$, $16.06 \%, 27.95 \%$ and $40.76 \%$ for thresholds from $-40 \mathrm{dBm}$ to $-75 \mathrm{dBm}$ respectively.
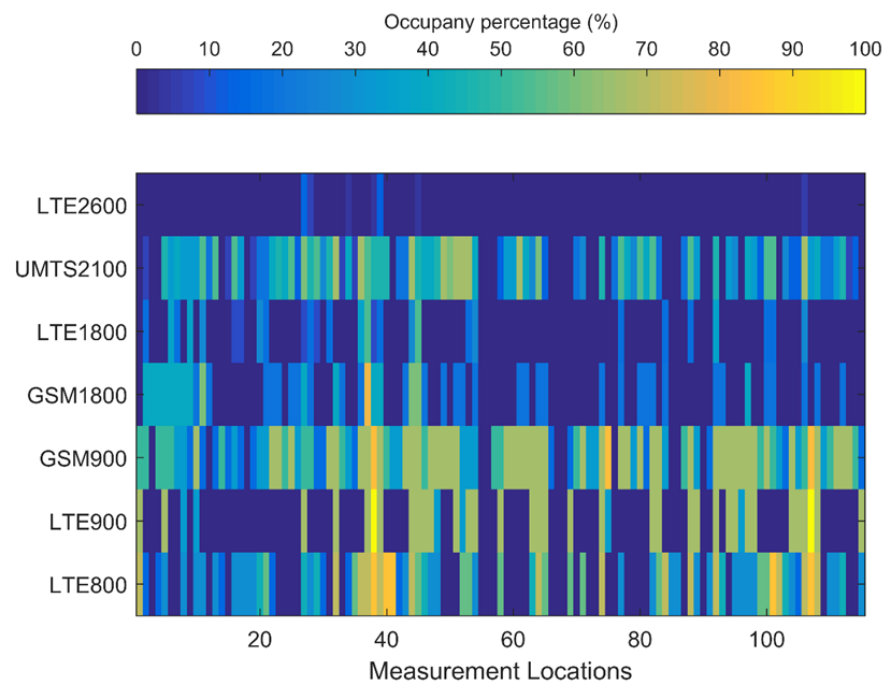

Fig. 3. Occupancy percentages at $-55 \mathrm{dBm}$ for EDT (a)

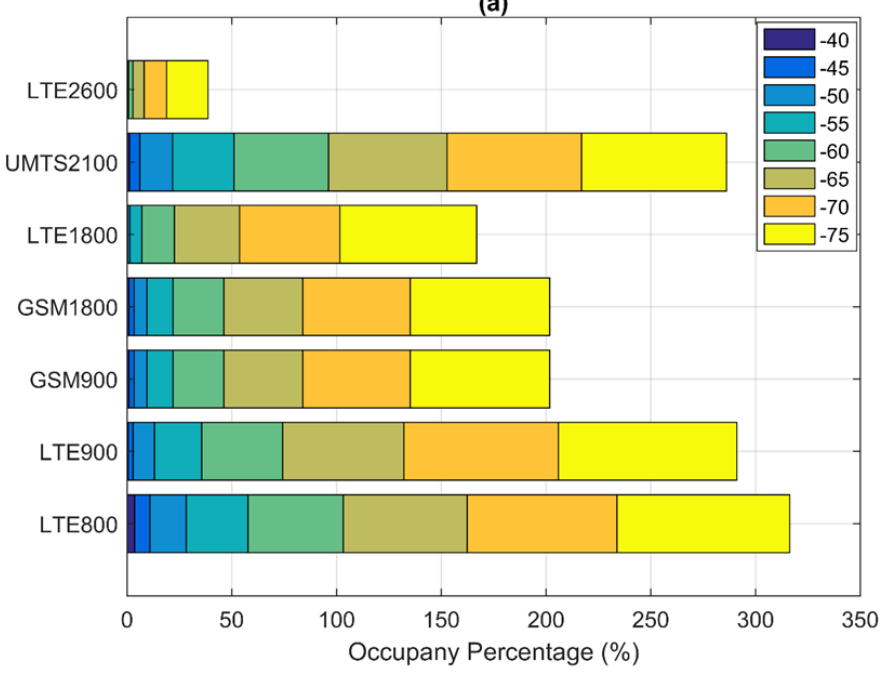

(b)

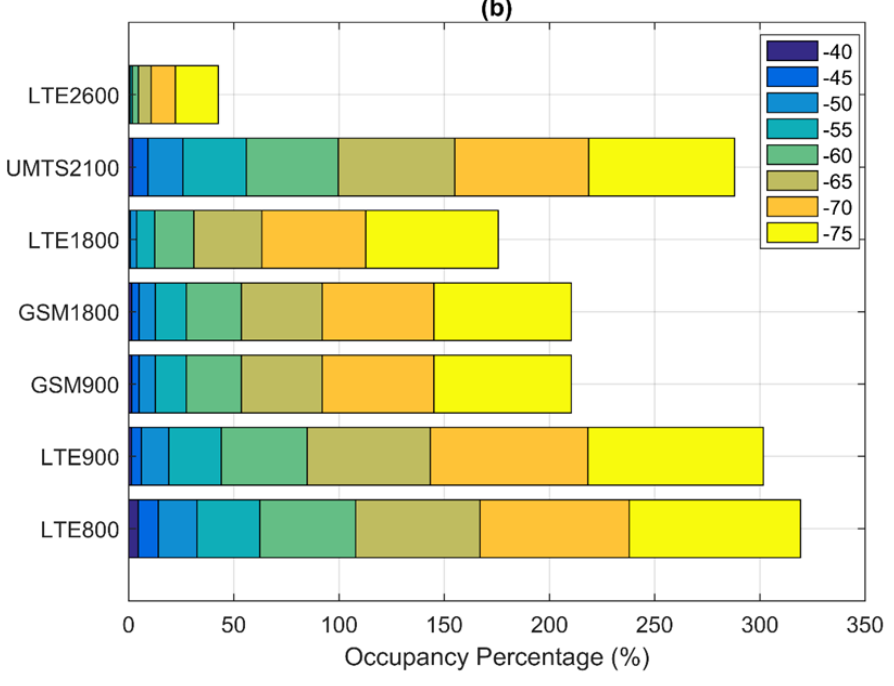

Fig. 4. Overall occupancy percentages for (a) EDT (b) ASOT

The decision thresholds were calculated according to the noise floor and ITU recommendation as $-52.85,-53.22,-48.83$, $-59.24,-60.79,-56.18$, and $-72.97 \mathrm{dBm}$ for the services LTE800, LTE900, GSM900, GSM1800, LTE1800, UMTS2100, and LTE2600 respectively. The occupancy percentages at these thresholds were calculated using EDT and ASOT, the results were given in Fig. 5.a and 5.b respectively. As seen from the figures that there are some slight differences at the measurement locations of i.e. 94,46 , and 52 for services of LTE900, LTE1800, and UMTS2100 respectively. However, occupancy percentages calculated through EDT and ASOT are closely follows each other, despite the difference in the calculation of spectrum occupancy. The differences between the results were in the range of $1 \%$ to $15 \%$. Therefore, both methods can be used for spectrum sensing, as they are both simple and easy to implement. 

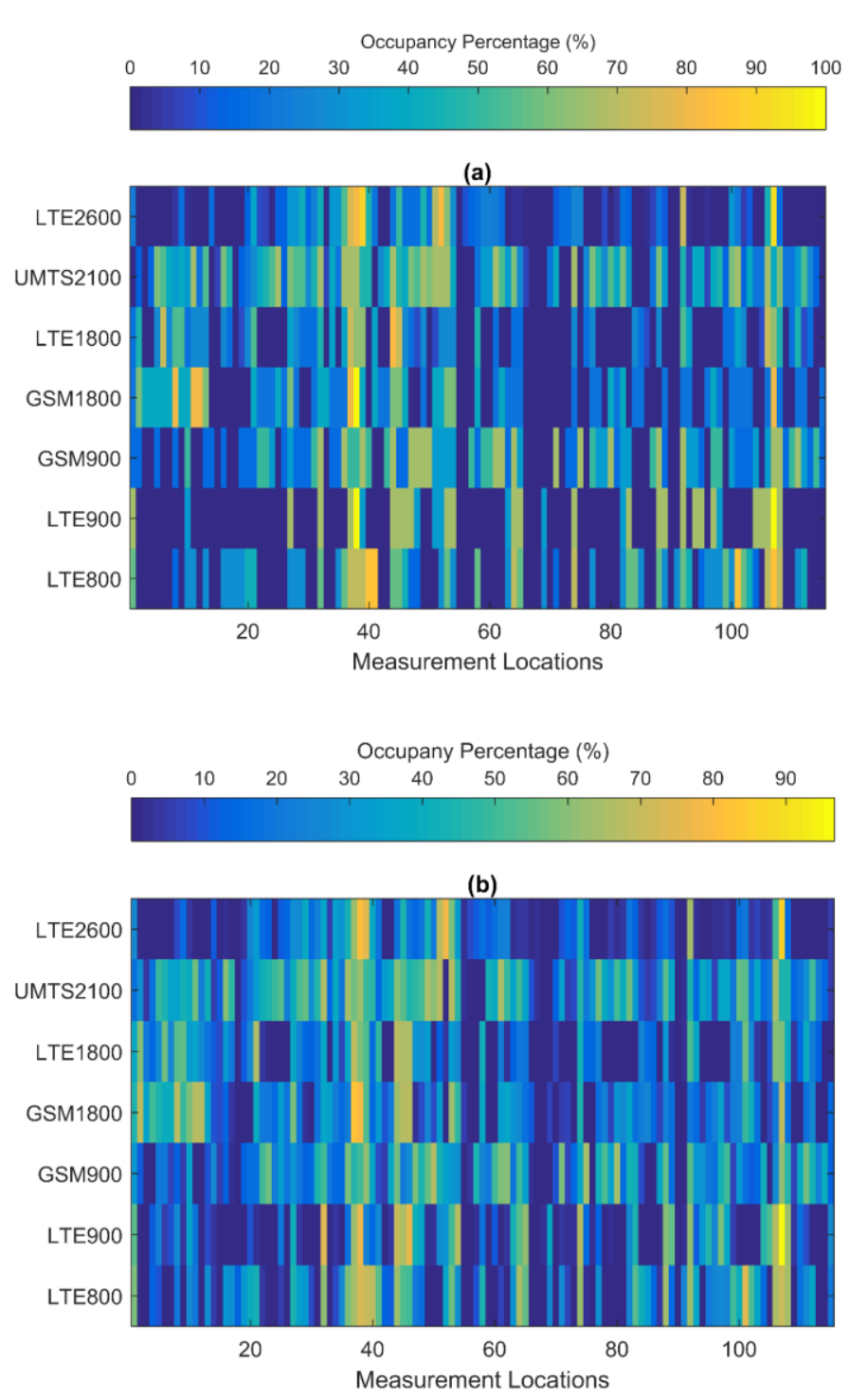

Fig. 5. Overall occupancy percentages at decision thresholds for (a) EDT (b) ASOT

Comparison of the overall average occupancy percentages were given in Table II. It can be concluded from the table that the average occupancy percentages calculated for all measurement locations through EDT and ASOT methods are almost equal. The maximum difference is obtained for the service of GSM1800 as $2.12 \%$.

TABLE II

THE TARGETED CELLULAR FREQUENCY BANDS

\begin{tabular}{|c|c|c|}
\hline Service Name & $\begin{array}{c}\text { Average } \\
\text { Occupancy } \\
\text { percentages for } \\
\text { EDT (\%) }\end{array}$ & $\begin{array}{c}\text { Average } \\
\text { Occupancy } \\
\text { percentages for } \\
\text { ASOT (\%) }\end{array}$ \\
\hline LTE800 & 23.48 & 23.83 \\
\hline LTE900 & 18.20 & 19.41 \\
\hline GSM900 & 27.83 & 27.07 \\
\hline GSM1800 & $\mathbf{2 1 . 7 4}$ & $\mathbf{2 3 . 8 6}$ \\
\hline LTE1800 & 17.94 & 19.73 \\
\hline UMTS2100 & 33.91 & 32.88 \\
\hline LTE2600 & 15.91 & 15.25 \\
\hline
\end{tabular}

Generalized cumulative distribution functions were given in Fig. 6.a and 6.b for EDT and ASOT respectively. As seen from the figures that in $50 \%$ of the measurement locations occupancy percentage is below $20 \%$ for the services of LTE900, LTE1800 and LTE2600, while above $25 \%$ for LTE800, GSM900, GSM1800 and UMTS2100. The results show that at $90 \%$ of measurement locations approximately $36 \%$ of the bands are vacant, and available for CR utilization.

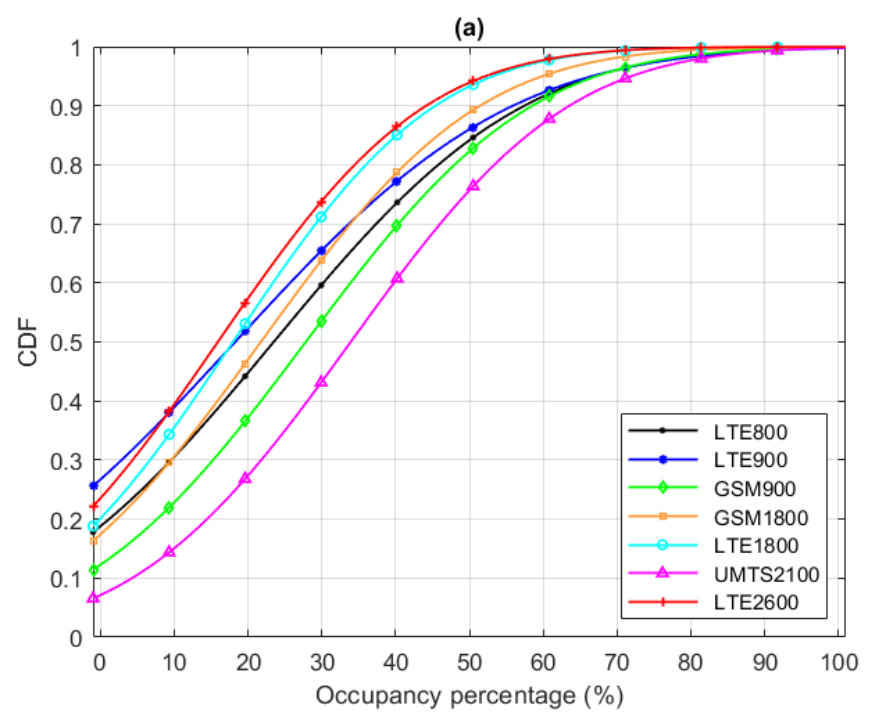

(b)

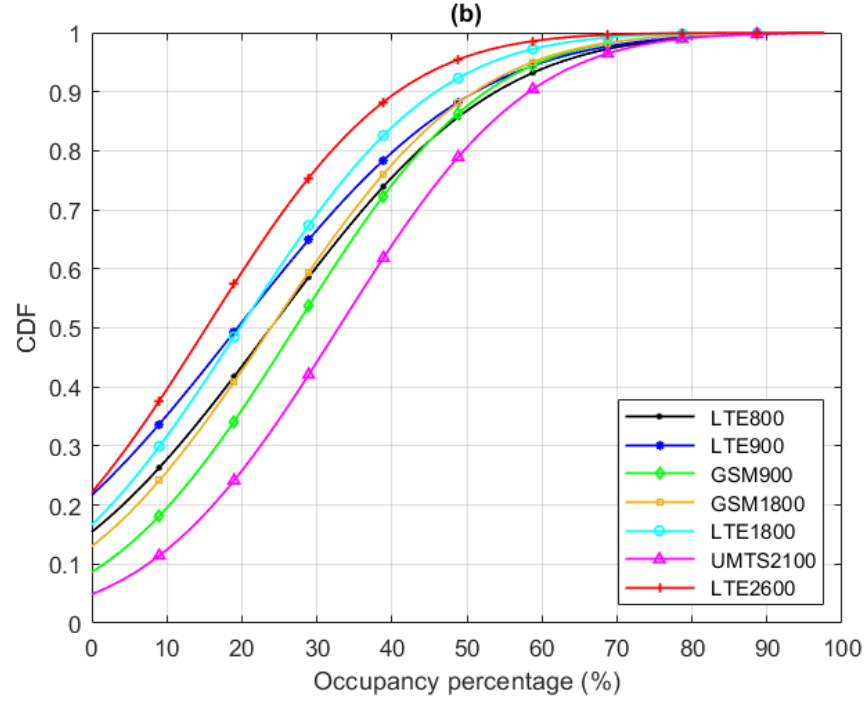

Fig. 6. Generalized cumulative distribution functions for (a) EDT (b) ASOT

\section{CONCLUSION}

In this study, to evaluate the availability of the cellular frequency bands, extensive spectrum measurements were performed in Samsun at 115 different locations. Energy detection and average spectrum occupancy techniques were used for spectrum sensing. In order to calculate the spectrum occupancy percentages, received signal energy was compared with the decision threshold which was chosen manually and according to noise floor. Evaluations and analysis show that 
spectrum utilization varies significantly by location and the service. Additionally, the maximum average occupancy of UMTS2100 is approximately $67 \%$, and utilization level of LTE2600 band is very low. Furthermore, average occupancy percentage of all services is $16.06 \%$ at $-55 \mathrm{dBm}$ threshold. Based on the mean occupancy percentages calculated, among the seven cellular bands UMTS2100 had the highest occupancy about $33 \%$ while LTE2600 had the lowest with about $15 \%$. The results show that $50 \%$ of the measurement locations occupancy percentage is below $20 \%$ for the services of LTE900, LTE1800 and LTE2600, while below 33\% for GSM900 and UMTS2100. The detailed analyses of the measurement results indicated that most of the bands are vacant and available for deployment of cognitive radio.

\section{REFERENCES}

[1] S. Grönroos, K. Nybom, J. Björkqvist, J. Hallio, J. Auranen and R. Ekman. "Distributed spectrum sensing using low cost hardware." Journal of Signal Processing Systems. 83:1, 2016, pp.5-17.

[2] M. S. Melo, G. R. Arroyave, and J. A. Quijano. "Spectrum Occupation Assessment in Bogota and Opportunities for Cognitive Radio Systems." IEEE-APS Topical Conference on Antennas and Propagation in Wireless Communications (APWC), 10-14 September, Cartagena des Indias, Colombia, 2018, pp. 932-935.

[3] F. Kiftaro, M. El-Tarhuni and K. Assaleh. "UHF Spectrum Occupancy Measurements in Sharjah-UAE." 9th IEEE-GCC Conference and Exhibition (GCCCE), 8-11 May, Sharjah, U.A.E, 2017, pp. 1-5.

[4] H. Maloku, Z. L. Fazliu, M. Ibrani, A. Mekuli, E. Sela and M. Rajarajan. "Measurement of Frequency Occupancy Levels in TV Bands in Urban Environment in Kosovo." 18th Mediterranean Microwave Symposium (MMS), 31 October. -2 November, Prishtina, Kosovo, 2018, pp. 268-271.

[5] C. Kurnaz, Z. Albayrak. "Measuring and evaluating TV white spaces in Samsun, Turkey." Journal of New Results in Science, 5, 2016, pp. 139148 .

[6] E. Wiles, K. Negus. "Long-term Spectrum Monitoring and Occupancy from 174 to $1000 \mathrm{MHz}$ in Rural Western Montana." 12th European Conference on Antennas and Propagation (EuCAP 2018), 9-13 April, Butte, USA, 2018, pp. 1-5.

[7] J. Popoola, U. Otuu. "Assessment of radio spectrum profile in Nigeria using multi-band and multi-location radio spectrum occupancy measurements." Eskişehir Technical University Journal of Science and Technology A - Applied Sciences and Engineering, 19 (4) , 2018, pp.948-962.

[8] I. Şeflek, E. Yaldız. "Spectrum occupancy measurements at University Campus in Turkey." International Journal of Electronics and Electrical Engineering, 5 (1), 2017, pp.1-6.

[9] A. Abdou, O. Najajri and A. Jamoos. "Developing a Secondary Mobile Network in the Palestinian GSM Band Using Cognitive Radio." 2017 IEEE Jordan Conference on Applied Electrical Engineering and Computing Technologies (AEECT), 11-13 October, Jerusalem, Palestine, 2017.

[10] B. K. Engiz, Y. A. Rajab. "Investigation of Spectrum Occupancy in GSM Band in Samsun, Turkey." 6th International Conference on Electrical and Electronics Engineering (ICEEE), Istanbul, Turkey, 2019, pp. 158-161.

[11] S. D. Barnes, P. A. Jansen van Vuuren and B. T. Maharaj. "Spectrum occupancy investigation: Measurements in South Africa." Measurement, vol. 46, no. 9, 2013, pp. 3098- 3112.

[12] G. Ayugi, A. Kisolo and T. W. Ireeta. "Telecommunication frequency band spectrum occupancy in Kampala Uganda. " International Journal of Research in Engineering and Technology, (4), 2015, pp.390-396.

[13] M. López-Benítez, A. Umbert and F. Casadevall. "Evaluation of Spectrum Occupancy in Spain for Cognitive Radio Applications." IEEE 69th Vehicular Technology Conference, 26-29 April, Barcelona, Spain, 2009, pp.1-5.

[14] J. Xue, Z. Feng and P. Zhang. "Spectrum occupancy measurements and analysis in Beijing. " IERI Procedia, (4), 2013, pp.295-302.
[15] D. A. Ramirez, M. Cardenas-Juarez, U. Pineda-Rico, A. Arce and E. Stevens-Navarro. "Spectrum Occupancy Measurements in the Sub-6 $\mathrm{GHz}$ Band for Smart Spectrum Applications." IEEE 10th LatinAmerican Conference on Communications (LATINCOM), 14-16 November, Mexico, 2018, pp. 1-6.

[16] N. Khoja, S. Anpat, V. Kale, P. Gadiya, S. Suryawanshi, M. Naikwadi and K. Patil. "Opportunistic Spectrum Access Measurements and Analysis in Urban Area for a Better Cognitive Approach." 2017 International Conference on Computing, Communication, Control and Automation (ICCUBEA), 17-18 August, Pune, India, 2017, pp.1-6.

[17] V. Valenta, R. Marsalek, G. Baudoin, M. Villegas, M. Suarez and F. Robert. "Survey on Spectrum Utilization in Europe: Measurements, Analyses and Observations." 2010 Proceedings of the Fifth International Conference on Cognitive Radio Oriented Wireless Networks and Communications, June 9-11, Cannes, 2010, pp.1-5.

[18] P. Chandhar and V. U. Pai. "On Collaborative Radio Frequency Observatory in India." 2020 IEEE International Conference on Advanced Networks and Telecommunications Systems (ANTS), New Delhi, India, 2020, pp. 1-6.

[19] F. Y. Ilgın. "Antenna Selection and Detection Performance on Correlation Based Detection Systems. " Balkan Journal of Electrical\&Computer Engineering, Vol. 9, No. 1, 2021, pp.48-52.

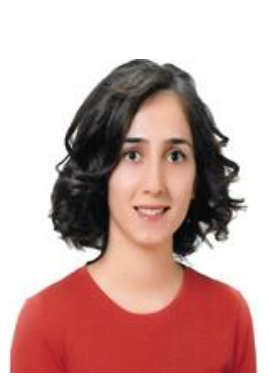

\section{BIOGRAPHIES}

BEGÜM KORUNUR ENGIZ She received the B.S., M.S. and PhD. degrees in Electrical and Electronics Engineering from Ondokuz Mayıs University, Samsun, in 2001, 2007 and 2014 respectively. From 2006 to 2011, she was a research assistant at department of Electrical and Electronics Engineering.: Between the years of 2011-2014 she was a lecturer at Ünye Vocational School, Ordu University. Since 2016 she has been an Assistant Professor Dr. at the Department of Electrical and Electronics Engineering, Ondokuz Mayıs University. Her research interests include wireless communication systems, cognitive radio, radio frequency electromagnetic field measurement and signal processing.

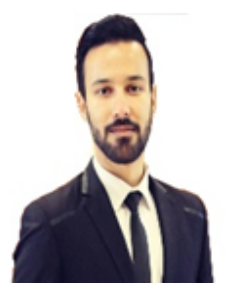

YOUSIF ALI RAJAB Iraq, Baghdad City, in 1991. He received the B.S. in computer engineering from Al Salam University college, Baghdad, and M.S. degree in Electrical and Electronics Engineering from Ondokuz Mayıs University, Samsun, in 2019. He is doing his Ph.D. on electronic engineering in Sakarya University. His research interests include cellular systems, cognitive radio and $4 \mathrm{G}$. 